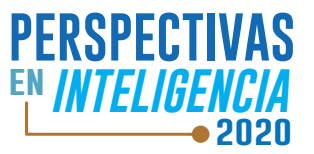

Revista científica en Ciencias Sociales e interdisciplinaria

Bogotá D.C., Colombia

Volumen 12, número 21, enero-diciembre 2020, pp. 129-150

https://doi.org/10.47961/2145194X.222

\title{
Exploración de la memoria y escenarios de reparación simbólica desde el caso colombiano
}

\author{
Memory exploration and symbolic reparation scenarios \\ from the colombian case
}

Pamela Pirateque Perdomo ${ }^{1^{*}}$ y Kelly Stefanía Ulloa Sánchez ${ }^{2}$

\begin{abstract}
(1) Escuela de Inteligencia y Contrainteligencia "BG. Ricardo Charry Solano" - ESICI, Bogotá - Colombia, pamela. piratequep@gmail.com

(2) Universidad Militar Nueva Granada - UMNG, Bogotá - Colombia, kellysulloas@gmail.com

* Autor a quien se dirige la correspondencia
\end{abstract}

\section{Resumen}

La memoria histórica es la representación de lo vivido y la forma de recordarlo para la posteridad, lo que implica que su desconocimiento, carácter subjetivo y descripción de los hechos son capaces de reafirmar o cuestionar lo sucedido en un determinado momento y espacio. El presente artículo busca profundizar sobre la influencia de la memoria en los escenarios de reparación simbólica, teniendo en cuenta la sociedad colombiana como un ejemplo de preservación de memoria doméstica en esferas internacionales, partiendo así del entendimiento del conflicto armado interno, su desarrollo, periodos y actores. Esto, a la luz de perspectivas académicas en las que se incluyan los distintos tipos de memoria (individual, colectiva e histórica) y el proceso de reparación simbólica en el marco del conflicto. Finalmente, se logra concluir que la preservación de la memoria sigue siendo un proceso constante en la sociedad, ya que trata de reconocer los hechos, de construir la verdad sobre los mismos y garantizar su reparación (simbólica). Al mismo tiempo, que trata de evitar la repetición de hechos bélicos que generen nuevas víctimas, y la negación de la memoria, construcción de nuevas realidades que evadan la versión real de lo vivido.

Palabras clave: Conflicto armado; memoria; reparación simbólica; víctimas.

\section{Abstract}

Historical memory is the representation of what was lived and the way of remembering it for posterity, which implies that its ignorance, subjective character, and description of the facts are capable of reaffirming or questioning what happened at a certain time and space. This article seeks to deepen on the influence of memory in the scenarios of symbolic reparation considering the Colombian society, as an example of domestic memory preservation in international spheres. Thus, starting from the understanding of the internal armed conflict, its development, periods, and actors. This, in the light of academic perspectives that include the different types of memory (individual, collective and historical) and the process of symbolic reparation in the context of the conflict. Finally, it is possible to conclude that the preservation of memory continues 
to be a constant process in society, as it tries to recognize the facts, deconstruct the truth about them, and guarantee their (symbolic) reparation. At the same time, it tries to avoid the repetition of war events that generate new victims, and the denial of memory, construction of new realities that evade the real version of what was lived.

Keywords: Armed conflict; memory; symbolic reparation; victims.

\section{Introducción}

La preservación de la memoria está ligada a los procesos de reparación individual (un solo individuo) y colectiva (un grupo de individuos), teniendo en cuenta un determinado espacio, tiempo y lugar. Así pues, Colombia se presenta como un caso de estudio en el que confluyen dinámicas sociales, políticos y criminales de vieja data (de más de cincuenta años) que cuentan con un trasfondo histórico que vale la pena rememorar. Esto se debe a la forma en que los grupos armados se han tomado el poder de territorios con precariedad estatal, como las regiones de Nariño, Arauca, Magdalena, Norte de Santander, entre otras, bajo el imaginario de cooptar funciones estatales y ejercer otros tipos de influencias a nivel regional y local ${ }^{33}$.

Tras la firma del Acuerdo de Paz en el año 2016, el Gobierno Nacional se propuso terminar con la presencia guerrillera en los territorios, escenario que sacó a la luz muchos hechos que habían quedado aislados de los estudios sobre el conflicto. Entre estos, la violación de derechos humanos hacia integrantes de las Fuerzas Militares de Colombia, la extorsión de mujeres y niños a favor de los intereses guerrilleros, los homicidios, las torturas, los atentados a la dignidad personal, entre otros. Esto llevó a que las víctimas revelaran sus experiencias a favor de la preservación de la memoria en el país, con el propósito de que no quedaran en el olvido los hechos devastadores que les trajo el conflicto armado y dejar un precedente para evitar su repetición.

Al hablar sobre memoria, reparación simbólica, conflicto y sociedad, se hace necesario conocer el proceso de Justicia y Paz propuesto por el gobierno de Juan Manuel Santos desde el año 2012 en Colombia, debido a que integra el marco de referencia jurídicosocial para analizar los avances en la preservación de la memoria de manera integral, reconociendo la existencia de la memoria individual, colectiva e histórica, en el entendido de que en un conflicto no solo se toman como víctimas a los protagonistas de la lucha armada. Más allá del Estado y los grupos criminales, existen múltiples víctimas o sujetos implicados, entre los que están: sociedad civil, minorías, grupos de interés, Fuerzas Militares y sus familias, entre otros actores que han vivido actos violentos $\mathrm{u}$ hostiles derivados por las tensiones del conflicto.

En este punto, preservar la memoria hace parte de un proceso determinante la deconstrucción del pasado y sus efectos en el presente. Al traslapar esto al caso colombiano, se evidencia una particularidad, los procesos de reparación y no repetición siguen vigentes, puesto que el conflicto interno al día de hoy sigue activo pese a la firma del Acuerdo de Terminación del Conflicto y la Construcción de una Paz Estable y

33 Ha sido tal su influencia en estas zonas del país que para el año 2019 se crearon las Zonas Futuro (ubicadas en cinco áreas: el Pacífico Nariñense, Catatumbo, Bajo Cauca y Sur de Córdoba, Arauca, Chiribiquete y parques nacionales aledaños) como parte de una estrategia para transformar los territorios, donde se busca llevar institucionalidad con legalidad, emprendimiento y equidad a las regiones más afectadas por la violencia, la criminalidad y la pobreza (Consejería Presidencial para las Comunidades, s.f.). 
Duradera con las Fuerzas Armadas Revolucionarias de Colombia (FARC). Las víctimas del conflicto no se sienten reparadas, tanto así, que aún viven con temor al conocer que los grupos subversivos continúan delinquiendo. Esto hace que el reconocimiento de las víctimas no se construya de manera colectiva y la reparación simbólica ligada a la memoria no cumpla los requisitos ${ }^{34}$ para que se efectúe a totalidad.

Este artículo se interesa por comprender los procesos de reparación simbólica haciendo uso de la memoria, pero no una memoria temporal o a corto plazo sino aquella que es continua y trasciende en el tiempo. Se tomará como base el conflicto colombiano, con el objetivo de aportar a la preservación de la memoria en instancias nacionales e internacionales. De acuerdo con lo anterior, la pregunta que guía este artículo es ¿cómo la memoria influye en los escenarios de reparación simbólica de la sociedad civil colombiana? Esto, considerando que la memoria ha ganado protagonismo al abrir espacios para conocer los relatos de las víctimas y victimarios (incluyendo su acompañamiento psicológico y emocional); exponer diversas perspectivas de los fenómenos inmersos en el conflicto (violaciones a derechos humanos, desplazamientos, injusticias, discriminación, etc.); ayudar a reconstruir hechos históricos; y, sobre todo, preservar los acontecimientos que se han desligado del conflicto interno en Colombia.

La memoria hace parte de la historia nacional, pero con una alta carga de subjetividad, ya que definir qué es lo que debe ser recordado y de qué manera, es una tarea muy difícil de cumplir objetivamente. Se debe abogar principalmente por la preservación de los hechos, situaciones, actores, episodios y demás elementos que puedan ser incluidos desde el conflicto. En aras de dar respuesta al interrogante, el texto se organizará de la siguiente manera: en primer lugar, se realizará un breve recorrido por la historia del conflicto armado colombiano, puntualizando en los momentos en los cuales se planeó negociar con los grupos criminales a favor de la paz; se tomarán las negociaciones de paz principales en las cuales hubo un cambio a favor de la construcción y futura preservación de la memoria en Colombia. En segundo lugar, se indagará sobre el concepto y las definiciones sobre memoria, para así poder conocer cada uno de sus tipos (histórico, individual y colectivo) y su aplicación en el contexto colombiano. En tercer lugar, se describirá la reparación simbólica, y sus vínculos con memoria y sociedad, y, por último, se esbozará unas conclusiones a partir de la temática expuesta.

\section{Metodología}

El presente artículo se basa en una metodología cualitativa, enmarcada dentro de un enfoque constructivista y descriptivo. El enfoque constructivista considera que el conocimiento se genera desde la estructura mental del individuo, ligada a la interacción con el medio. Además, según Wesley (1982), el enfoque cualitativo descriptivo se relaciona con las condiciones o conexiones existentes: prácticas, opiniones, puntos de vista o actitudes, lo que se complementa con la revisión de diferentes documentos sobre la preservación de la memoria, haciendo uso de la reflexión generada en espacios de diálogo entre las víctimas y victimarios del conflicto.

34 Los requisitos o medidas de satisfacción y reparación simbólica se establecen mediante la Ley 975 de 2005, en la cual destacan: el reconocimiento público del carácter de víctima, de su dignidad, nombre y honor, ante la comunidad y el ofensor, actos conmemorativos, apoyo a la reconstrucción del movimiento y tejido social de las comunidades campesinas, contribuir a la búsqueda de los desaparecidos, entre otros (Subcomité Técnico de Medidas de Satisfacción, 2011). 
Lo cual es fundamental para iniciar los procesos de reparación simbólica por medio de la narrativa de la memoria y, consecuentemente, su preservación en el tiempo (Centro de Escritura Javeriano, 2018).

\section{Construcción de la memoria desde el escenario de conflicto colombiano}

Para conocer la memoria desde el escenario del conflicto armado colombiano, se hace necesario un breve recuento histórico. De esta forma se resaltan los periodos, hechos, actores y momentos específicos, en los que se planearon posibles negociaciones con los grupos subversivos que sirvieron de base para la deconstrucción de la memoria y su preservación en la actualidad. Hablar de esto requiere traer a colación un recuento breve del escenario del conflicto armado que ha vivido Colombia por más de cincuenta años. Autores como Jerónimo Ríos, en su texto Breve historia del conflicto armado en Colombia (2017), presenta el desarrollo del conflicto armado desde 1940, época llena de tensiones como las luchas bipartidistas, el bogotazo entrado el siglo XX, la instauración del Frente Nacional, entre otros momentos que fueron enmarcando poco a poco la construcción del conflicto colombiano.

Sin embargo, el presente artículo tomará el surgimiento del conflicto a partir del establecimiento de las guerrillas en los años sesenta, específicamente en 1966 con el nacimiento de las Fuerzas Armadas Revolucionarias de Colombia (FARC). Eso se debe a que con el surgimiento de esta guerrilla comenzaron a crecer los episodios de violencia en el territorio nacional. Ejemplo de ello, son los bombardeos como el de Marquetalia en 1964, donde los campesinos que habían sido liberales tomaron las armas bajo el mando del Partido Comunista Colombiano, comenzando así a expandir problemáticas estructurales como pobreza regional y desplazamientos masivos en todo el territorio (Centro Nacional de Memoria Histórica, 2014).

Esta desestabilización influyó en que organizaciones ilegales se fortalecieran y crearan mayor independencia, principalmente a través del negocio del narcotráfico, junto con presiones de grupos subversivos, por medio de medidas como la extorsión (Antón, 2017). Entre 1974 y 1991 el Gobierno Nacional formuló reformas como la Constitución Nacional, expresada en la Asamblea Nacional Constituyente (ANC) de 1991, la cual generó un panorama con mayor tensión, puesto que los actores criminales del conflicto como las FARC y el Ejército de Liberación Nacional (ELN) no hicieron parte del proceso, por lo que esta democratización no resolvió el problema de violencia política (Hurtado, 2006). En 1978 inicia la etapa de represión política y armada bajo el mandato del presidente Julio César Turbay Ayala (1978-1982), quien promulgó con el Partido Liberal el Estatuto de Seguridad, donde se instauró el Comité Permanente por la Defensa de los Derechos Humanos (CPDH), primer paso para velar por el reconocimiento de las víctimas del conflicto armado y la reparación de sus derechos (Montoya, s.f.). No obstante, esta normatividad continuaba generando exclusión socioeconómica y falta de espacios para la libre participación política (Barcelona Centre For International Affairs, s.f.).

En 1980 se involucran nuevos actores, como los grupos paramilitares, bajo la Ley 48 de 1968, la cual permitió la privatización de la lucha armada a manos de civiles protegidos por intereses de élites regionales (Barcelona Centre For International Affairs, s.f.). La lucha constante entre paramilitares y guerrilleros provocó la participación de las 
Fuerzas de Seguridad, entre ellas: Fuerzas Militares (Ejército, Armada y Fuerza Aérea) y Policía Nacional, quienes iniciaron una lucha contra grupos insurgentes haciendo uso de la Doctrina de Seguridad Nacional, que tenía el objetivo de erradicar la amenaza comunista usando cuerpos de seguridad antiterroristas y asistencia para el desarrollo (Barcelona Centre For International Affairs, s.f.).

Entre 1998 y 2002 se da el primer fracaso representativo para la construcción de memoria en las negociaciones de $\mathrm{paz}^{35}$. El Proceso del Caguán, propuesto por Andrés Pastrana para terminar el conflicto con las FARC, pretendía iniciar un proceso de paz y la construcción de memoria nacional. La política de Pastrana se inscribe en el ciclo de militarización de la política, lo cual se ve como un fracaso para las negociaciones de paz, pero al mismo tiempo da las bases para la politización de la guerra ${ }^{36}$ (Loaiza, 2012). Tras este suceso, el Gobierno había desmilitarizado 42.000 kilómetros de la región del Caguán (departamento del Caquetá), por lo que las guerrillas tomaron ventaja, principalmente en los territorios de La Uribe, Mesetas, Vista Hermosa y La Macarena (departamento del Meta). El Estado se encontraba fragmentado, puesto que estaba perdiendo control de zonas territoriales estratégicas para recuperar el control estatal, en tanto que eran (y al día de hoy lo son) puntos centrales en donde se desarrollan actividades ilícitas y se asientan grupos subversivos.

Desde 1998 continuaron presentándose dinámicas que demarcaban la situación del país, es decir, un Estado envuelto en la desigualdad, la pobreza y la criminalidad (Serrano, 2018). Los escenarios se centraron principalmente en el narcotráfico y economías ilegales. Sin embargo, Álvaro Uribe Vélez, en 2002, inicia un proceso de militarización tras la Política de Seguridad Democrática, donde se dieron logros en la disminución de la violencia social, debido también al control de nuevos grupos ilegales dedicados al narcotráfico y no a violentar la vida de los ciudadanos, y a los cambios en la estructura castrense, que van desde capacitación hasta adquisición de equipos para continuar con la ofensiva militar. Sin embargo, esta iniciativa también incidió en que la presencia de grupos paramilitares atentara contra miembros de las Fuerzas Militares, como retaliación por iniciar una lucha contrainsurgente o contraterrorista (Antón, 2017). En este punto, se debe tener en cuenta que tantos los miembros de las Fuerzas Militares como sus familias también son víctimas del conflicto armado y hacen parte de la preservación de la memoria.

A partir de 2005 se logra la desmovilización de las Autodefensas Unidas de Colombia (AUC) y se avanza en el fortaleciendo de las Fuerzas Militares, dando como resultado el reacomodo del conflicto armado y la creación de una ofensiva militar que alcanza su máxima eficiencia en acción contrainsurgente. No obstante, esto hace que los grupos insurgentes busquen nuevas formas de contraatacar, aumentando su acción criminal y

35 Es importante tener en cuenta que Colombia ha tenido una serie de procesos de negociación de paz antes del Proceso del Caguán, entre ellos: La Comisión de Paz de Julio César Turbay en 1981; inicios de negociación de paz en 1982 y el Acuerdo de La Uribe en 1984, de Belisario Betancur; diálogos de paz con las FARC y el M-19 por parte de Virgilio Barco en 1988 y el logro de firmar un acuerdo de paz con el M-19 en 1990; conversaciones con las FARC y el ELN en el gobierno de César Gaviria en 1991, más su logro de reintegrar a la Corriente de Renovación Socialista (disidencia del ELN) a la vida civil en 1993; la sesión del espacio político al ELN en el gobierno de Ernesto Sampen en 1998; diálogos de paz con las FARC en el período presidencial de Andrés Pastrana en 1999; ofensiva militar con apoyo de Estados Unidos contra las FARC y el ELN en el gobierno de Álvaro Uribe en el año 2002; finalmente, el proceso de negociación y final estructuración del Acuerdo de Paz con las FARC en el gobierno de Juan Manuel Santos, desde el año 2012 (Barcelona Centre For International Affairs, s.f.).

36 La politización de guerra se refiere a la política orientada hacia acciones de guerra: luchas guerrilleras con acciones violentas legitimadas por una causa que involucra la confrontación política. 
haciendo uso de técnicas más desafiantes frente al Estado (aumenta la violencia contra la sociedad civil y líderes políticos) (Centro Nacional de Memoria Histórica, 2014).

Para el año 2010, Juan Manuel Santos asumió la presidencia de un país polarizado, debido a la crueldad de la guerra y las dificultades para aplacarla (Antón, 2017). Este ambiente de crisis abrió la posibilidad de establecer diálogos con las FARC y estructurar el Acuerdo para la Terminación del Conflicto y la Construcción de una Paz Estable y Duradera, a favor de la reparación de cada una de las víctimas afectadas por la disputa interna, además de impulsar la preservación de la memoria histórica nacional. Para preservar la memoria se involucran tanto víctimas como victimarios que deberán iniciar un proceso de reincorporación a la vida civil, mientras el Estado fortalece su democracia y sus instituciones con el fin de establecer un ambiente de paz (Antón, 2017).

El conflicto armado colombiano representa la circunstancia más compleja y dolorosa en la historia del país, ya que la sociedad civil ha vivido en un escenario de incertidumbre durante más de medio siglo y su desarrollo se ha visto envuelto en espacios de miedo y zozobra (Vásquez, 2015). El escenario heterogéneo del conflicto implica la participación de distintos actores, quienes se han vuelto historiadores, narrando la historia de lo que han vivido. Estas historias o narraciones permiten ver el trasfondo de las violaciones a los derechos humanos, las injusticias en sus casos e incluso el tiempo que ha transcurrido para dar respuesta sobre lo sucedido. Tan solo entre 1997 y 2003 se realizaron 77 masacres en Colombia, donde la Corte Interamericana solo ha pronunciado 10 sentencias a las graves violaciones de derechos cometidas por los grupos armados (Caraballo \& Anaya, 2016).

La preservación de la memoria integra los relatos de las víctimas y victimarios, los hechos hostiles, la deconstrucción de escenarios y la preservación de lo vivido en el país. En otras palabras, la preservación de la memoria en el conflicto colombiano es una convergencia de voluntades y esfuerzos estructurados por rememorar un pasado conjunto en las trayectorias de sus vidas (Centro Nacional de Memoria Histórica, 2018). Razón por la cual se han creado distintos espacios para preservar la memoria, dentro de los que están: el Centro Nacional de Memoria Histórica y el Centro de Investigación en Memoria Histórica Militar. (Centro Nacional de Memoria Histórica, 2018). Sin embargo, para entender con mayor detalle la trascendencia de la memoria (y su preservación) en la sociedad colombiana, la primera tarea es generar una aproximación conceptual sobre su definición y elementos integrados.

\section{La preservación de la memoria como medida de reparación simbólica}

El conflicto armado ha sembrado escenarios de miedo e incertidumbre en todo el país, involucrando a distintos actores que hacen parte de la historia nacional. Los diálogos de paz han construido subescenarios del conflicto en los cuales se espera alcanzar la reparación de cada una de las víctimas. Uno de estos es la preservación de la memoria, un espacio en donde los hechos y relatos importan como mecanismo de recordación, no olvido y búsqueda de formas de reparación física o simbólica.

En este punto, se hace necesario definir ¿qué es memoria?, con la intención de conocer su uso, la influencia que puede tener, sus tipos, el papel de las víctimas, el uso de narrativas y su necesidad de preservación en la sociedad civil. La memoria es un 
proceso tan antiguo como la existencia del mismo hombre. La memoria se desarrolló a través del arte. Tras la aparición del lenguaje cobró relevancia en la tradición oral, se volvió imprescindible y constante para la literatura. La relación entre memoria y literatura consistió en la acción de ambas para construir conjuntamente, modificar y significar la realidad individual y la realidad colectiva/social (Gutiérrez, Andrade, Huérfano, \& Cañón, 2017). La obra de Halbwachs (1968) se refiere a la memoria como la construcción de relatos producto de la sucesión de eventos individuales, en donde los grupos establecen relaciones por medio de una distinción común, en este caso, los hechos sufridos producto del conflicto armado (Echeverry, 2004).

Desde los aportes de Leonardo Latorre Iglesias (2010), cada historia de las víctimas sirve para dejar la victimización atrás y empoderarla de sus propios relatos, los cuales aportan a que este reclame sus derechos y comience un escenario de reinvención de sus proyectos de vida (Iglesias, 2010). La memoria se muestra como una herramienta para impulsar espacios de verdad, reconocimiento de hechos (en su mayoría traumáticos), identificación de víctimas, reconstrucción de narrativas y una mirada general al pasado para construir el futuro. ¿Cómo empieza a construirse y preservarse la memoria?, su interés parte en la década de 1980 desde Europa y Estados Unidos, a causa de los debates en torno al Holocausto y la expansión mediática de sucesos como: el ascenso de Hitler al poder en 1933, la conferencia de Wannsee de 1942 (reunión de civiles, policiales y militares en la Alemania Nazi), la invasión de Normandía en 1994, entre otros.

Desde este acercamiento académico-político, la memoria se convierte en una vertiente eurocéntrica. El sociólogo francés Maurice Halbwachs enfatiza en que la memoria procede de una comunidad, un tiempo, un lenguaje y un espacio concreto (Revelo, 2019). Con lo cual, los genocidios en Ruanda, Bosnia y Kosovo reforzaron el discurso del holocausto a nivel global; dejando de paso un referente sobre lo sucedido y espacios de concienciación sobre cada uno de estos hechos. Por su parte, la llegada memorialista a América Latina se dio a través de Chile y Argentina, presentándose como una necesidad por cerrar el capítulo de terrorismo de Estado ${ }^{37}$. La expansión de la cultura de la memoria fue cambiando simultáneamente con los usos políticos desde diferentes enfoques ideológicos, incluso llegando al punto de ser espacios museificados, expuestos ante la sociedad como piezas de un contexto o temática específica y llegando finalmente a ser empleada (la memoria) como parte de los procesos o políticas de reparación de víctimas en países afectados por el conflicto como Colombia (Huyssen, 2002).

Desde el enfoque psicológico, la memoria se retoma como un proceso de construcción de la realidad y se aborda desde tres distintas perspectivas. La primera, es el conductismo, que se refiere a formulaciones cognoscitivas en las que la memoria es vista como una función mental para recuperar la información. La segunda, es el psicoanálisis (la tradicional), en el cual se creía que la recuperación del recuerdo traumático permitía la cura del sufrimiento psíquico (Gutiérrez, Andrade, Huérfano, \& Cañón, 2017). La tercera, los enfoques actuales, expresan la memoria como aquello que constituye la mente humana en amplias posibilidades, donde lo importante no es cómo ocurrió

37 No existe un tipo penal que defina el terrorismo de Estado, pero se conoce este cuando proliferan medidas gubernamentales sistemáticamente represivas, criminales y en general de tipo autoritario contra los conciudadanos, considerándolos como enemigos de Estado (Vásquez, El concepto de terrorismo de Estado: una propuesta de Lege Ferenda, 2010). 
sino la forma en la cual la persona vive lo ocurrido (Gutiérrez, Andrade, Huérfano, \& Cañón, 2017).

Conviene subrayar que para crear memoria es necesario saber quéclase de deconstrucción o preservación se llevará a cabo, con la recolección de los relatos de los sucesos, y su respectivo tiempo, modo, actor y lugar. Este proceso tiene tres formas de expresarse: histórica, individual y colectiva. Cada etapa aporta para comprender lo sucedido y resignificar el dolor de las víctimas (Iglesias, 2010). Estas expresiones se forman debido a que la conciencia no es cerrada, sino que se presenta en direcciones múltiples, es decir, que cada individuo recuerda o crea una realidad sobre un momento de forma diferenciada. Si se piensa lo anterior, en un período de crisis constante (o conflicto que ha acontecido en conflicto colombiano), existen múltiples interpretaciones sobre lo vivido que incluyen poblaciones y territorios.

En este caso, la memoria se toma como un punto de partida sobre el cual se puede continuar profundizando, tanto así que a continuación, se explica con mayor profundidad cada tipo de memoria, teniendo en cuenta el punto de vista de diversos autores y académicos. Lo que a su vez se relacionará con las diversas formas de reparación simbólica, entre ellas, la atención psicosocial, el diálogo y el reconocimiento como víctima (lo anterior, en el marco del conflicto armado interno).

\section{La memoria en la historia: memoria histórica}

María Emma Wills (2018) expresó en un artículo del CNMH qué se habla cuando se menciona memoria histórica. De modo general, la memoria histórica se percibe como distintas narrativas que construyen una secuencia sobre situaciones específicas de un pasado desde un presente que marca a su vez el futuro (Centro Nacional de Memoria Histórica, 2018). La memoria histórica da una mirada diferente al pasado y cambia la perspectiva del futuro. Es decir, la historia habla del pasado, pero también sobre las personas que vivieron allí. La revisión de los hechos se encuentra comprometida con una historia en común, su estructuración se hace a través de una ruta que permite desarrollar conexiones entre una historia particular y una historia colectiva.

La no-construcción de memoria o la negación de la misma, se presta para que las nuevas generaciones que no vivieron ciertos momentos históricos cuenten con un vacío de información sobre lo sucedido. Ejemplo de ello, son las nuevas generaciones de niñas, niños y jóvenes en Colombia que no conocen el impacto de la violencia y el conflicto, debido a su minimización en espacios escolares o familiares (Centro Nacional de Memoria Histórica, 2018). La consecuencia de dejar espacios sin llenar se asemeja a la frase de Napoleón Bonaparte: "Aquel que no conoce su historia está condenado a repetirla". Además, se podrían justificar las violaciones a las víctimas a causa del desconocimiento social, e incluso construir nuevas memorias de lo sucedido que cambien totalmente el significado de los eventos.

Con el fin de que la memoria tome fuerza, la autora propone un entendimiento sobre el pasado enfocado en el testimonio de las víctimas, puesto que estos tienen un poder transformador e inspiran solidaridad desde las vivencias cotidianas. La memoria toma fuerza por la capacidad que tiene de convocar a las personas sobre un mismo hecho, de recrear las experiencias vividas por otras personas en un determinado territorio y, desde ahí, construir un escenario en el que se puedan expresar las diferencias sin crear 
un arrasamiento mutuo (Centro Nacional de Memoria Histórica, 2018), al aceptar que la memoria histórica supone una reconstrucción de los hechos que proporcionan las víctimas en el presente sobre su pasado (Echeverry, 2004). Se puede confirmar que la memoria es un giro hacia el pasado (Marín, 2011), aquello que repercute en la formación de la historia, le da relevancia al recuerdo y al olvido en la escena pública y demuestra una preocupación cultural y política por lo acontecido (Huyssen, 2002).

En el caso particular de Colombia, la memoria histórica se da como un derecho fundamental. Desde la teoría de Robert Alexy, aceptada por la Corte Constitucional colombiana, los derechos fundamentales son mandatos de optimización y parten de la libertad, igualdad y dignidad. Esto hace que sean una expresión de la comunidad, un mensaje comunicativo que vincula a todos los integrantes para que se respeten entre sí y se pueden desarrollar en sociedad (Camacho, 2018). En relación con la memoria histórica, esta cumple la función de reformar la no repetición de conductas del conflicto, he ahí su punto en común con los derechos fundamentales. La memoria refuerza el mensaje a la sociedad de las víctimas y victimarios, la verdad sobre los fenómenos violentos, el reconocimiento de hechos y actores participantes y la reconstrucción de historias, garantizando además la pacificación social y la posibilidad de ejercer todos los derechos (Camacho, 2018).

\section{Desde los instintitos propios hasta la memoria: memoria individual}

En el caso de la memoria individual, esta fue tratada por la psicología desde el siglo XIX. El psicólogo William James distingue entre memoria primera y secundaria, lo cual se traduce en memoria a corto y largo plazo. Estos tipos de memoria aportaron al desarrollo de la psicología cognitiva, que retoma la memoria como un tema central de las reflexiones a través de la percepción y el razonamiento (Brito \& Martínez, 2005). Desde el enfoque sociológico, Maurice Halbwachs (2004; 2011), postuló que este tipo de memoria está inscrita en marcos de referencia colectivos. El pasado se reconstruye mediante un proceso de selección e interpretación, en el que la memoria individual se expresa en un grupo social con narraciones biográficas identitarias (Siedl, s.f.).

La memoria individual es considerada como la narración de personas según lo que han vivido, historias llenas de sentimientos, subjetividad y olvidos que revelan situaciones particulares y propias. Se puede comparar este tipo de memoria con las libertades individuales, las cuales se viven de manera interna y dependen de cómo las recrea cada individuo (Ávila, 2013). Según Halbwachs (1968), la memoria individual se opone a la memoria colectiva, es condición necesaria para el reconocimiento de recuerdos internos, pero no suficiente para los recuerdos externos. Así las cosas, puede ser tomada como un punto de apoyo, puesto que genera una aproximación sobre una temática en particular desde el individuo, sin embargo, no representa una construcción colaborativa de lo vivido por un grupo de personas.

En el caso de Colombia, se tomarían los relatos de las víctimas de manera individual y se hallarían diversas perspectivas del conflicto, en tiempo, modo y lugar. Por ejemplo, con las afectaciones según la población étnica, por género, según edades u otros rasgos característicos más específicos, lo anterior, sin incluir los lugares donde se perpetraron los hechos. No obstante, este proceso tiende a volverse colectivo, ya que son personas que vivieron el mismo conflicto armado, claro está, desde diferentes orillas, lo que 
si bien no da un mismo resultado o se llega a un mismo camino, si logra generar un aporte enriquecedor para entender las lógicas hostiles, sus efectos en la sociedad y sus aportes para el futuro.

\section{Un conjunto de experiencias convertido en memoria: memoria colectiva}

En este punto, se debe tener en cuenta que los relatos individuales no se han podido integrar en relatos amplios (Gómez, 2013). La memoria colectiva, al ser una construcción social que involucra la participación de un grupo para recordar y narrar desde un punto en común, plantea que los relatos vividos en un mismo contexto deben compartir características propias del momento (cuándo, cómo, por qué, quién, etc.) (Ávila, 2013). Halbwachs expresó en su texto La memoria colectiva (1950) cómo existe una relación de esta memoria con la individual, la histórica, el tiempo y el espacio (Siedl, s.f.); desde el interior se pueden establecer oposiciones entre memorias, pero la memoria colectiva (externa) no tiene esa posibilidad, eso la convierte en una construcción más amplia. Se podría decir que es una versión integradora de diversas realidades.

La construcción de memoria será colectiva en la mayor cantidad de casos, puesto que los recuerdos son públicos-sociales-comunitarios e incluyen a más de un actor. Esta construcción se llama memoria social, o conociendo que se basa en el conjunto de relatos individuales, se convierte en memoria histórica (Halbwachs, 1991). No obstante, existen diferencias entre la memoria colectiva y la historia. Para empezar, la memoria colectiva es una corriente de pensamiento continuo; en el caso de la historia, cuando un período de tiempo no tiene el mismo interés se cierra y se establece un rango limitado, además, en este punto pueden participar otros grupos de personas con diferentes realidades. Asimismo, otra diferencia es que existen múltiples memorias colectivas, cada uno de los grupos posee una historia (Estado, actores políticos, iglesia, FF.MM., campesinos, indígenas, mujeres, afrocolombianos, LGTBI, etc.), trayendo consigo una cosmovisión propia sobre cómo se ve y entienden los fenómenos (Halbwachs, 1991).

Fue hasta el siglo XXI cuando se manifestó con mayor fuerza la reflexión de la memoria en Colombia, este escenario fue denominado el "Boom de la memoria" y se vio representado en el aumento de iniciativas no oficiales que hicieron frente al conflicto. Estas iniciativas se pueden ver reflejadas en reflexiones y trabajos académicos de grupos de memoria y el auge de producciones culturales entorno a la temática (Giraldo, 2012). La edificación de memoria se basa en abordar el pasado no resuelto desde los escenarios de conflicto, en el cual se involucran las víctimas y la sociedad civil que reclaman al Estado justicia y garantías de no repetición, evidenciando la configuración de la memoria colectiva (Giraldo, 2012).

En la construcción de memoria colombiana, hablar de memoria colectiva supone la recolección de los relatos de los actores implicados en el desarrollo del conflicto, aportando a la preservación de la historia desde la narración de sus experiencias y ayudando a la deconstrucción de lo ocurrido en un periodo en específico. La figura 1 trata de introducir los tipos de memoria mencionados anteriormente, además de evidenciar cómo la comunicación entre ellos es un factor clave en cada uno de estos procesos. Esto se debe a que la conexión de las memorias individuales da como resultado la memoria colectiva y, finalmente, la memoria colectiva impulsa la preservación de la memoria histórica. 
•FIGURA 1• Tipos de Memoria

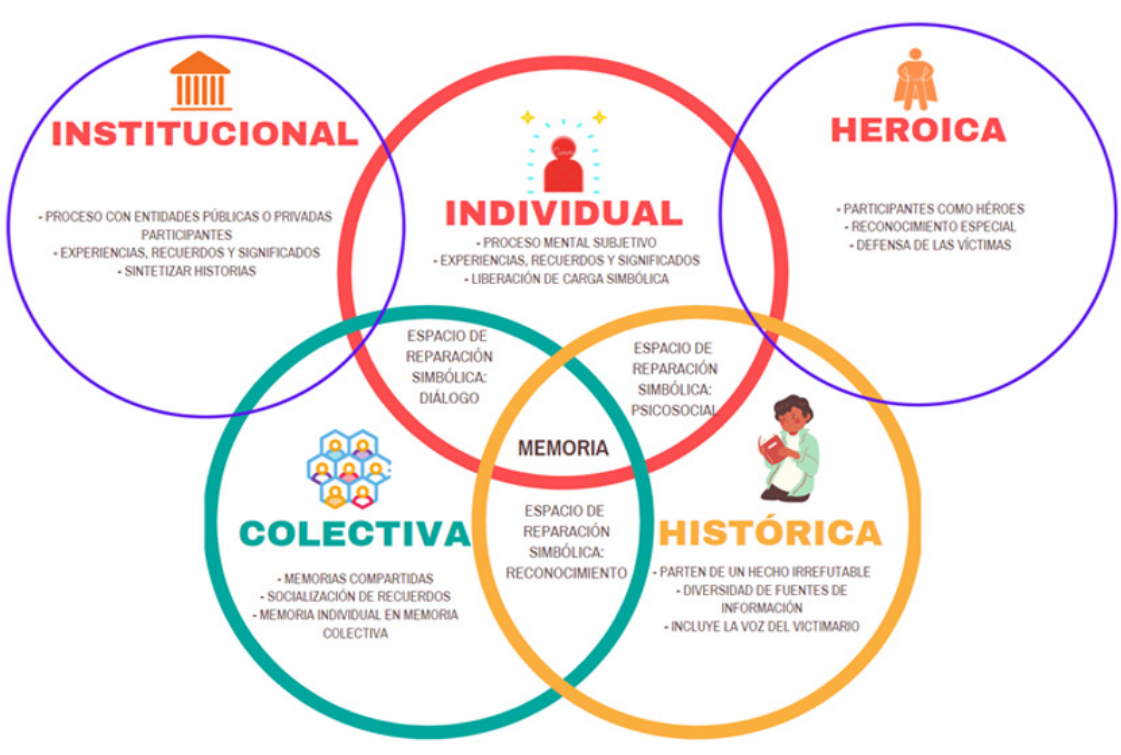

Fuente: elaboración propia

Es necesario resaltar la existencia de otros tipos de memoria, como la memoria histórica institucional y la memoria heroica que, a pesar de no estar consignadas en la Ley 1448, son relevantes en la preservación de los hechos y la verdad. La memoria histórica institucional se refiere a la documentación de los hechos ocurridos durante el conflicto armado, en los cuales se vieron afectados integrantes de las instituciones públicas, como la Policía Nacional de Colombia y sus familias. Esta memoria busca recopilar y sistematizar las historias y relatos de las personas afectadas por la violencia, con el fin de generar espacios de reparación simbólica institucional y social (Policía Nacional de Colombia, 2020).

En cuanto a la memoria heroica, como su nombre lo menciona, implica construir una imagen heroica de los participantes del conflicto, principalmente aquellos que se dedicaron a defender a las demás víctimas. Se busca mostrar como héroes a ciertos grupos o individuos, resaltando a su vez su simbología y demás expresiones propias de la institución a la cual pertenecen (Aránguiz, 2014). Considerar estos tipos de memoria es fundamental para analizar casos como el Holocausto en Alemania, en el cual, a pesar de iniciar procesos como los juicios de Nuremberg, se sugiere tener en cuenta la perspectiva y los casos puntuales de entes institucionales, siendo estos los principales ejecutores y cómplices del Holocausto, entre ellos jueces, policías, Ejército, complejos industriales, iglesias, docentes, personal de la salud y gran parte de la sociedad alemana (ElCorreoGallego, 2019). 
Otro caso es la Ley 52 de 2007 o Ley de Memoria Histórica española, la cual manifiesta la importancia de recopilar la memoria institucional en contextos de perturbación, un ejemplo de ello es la Guerra Civil española. Esta Ley es formulada con el objetivo de reconocer y ampliar los derechos a favor de quienes padecieron de persecución o violencia, por razones políticas, religiosas o ideológicas durante la Guerra Civil y la dictadura (BOE Legislación Consolidada, 2007).

\section{Procesos de reparación simbólica: un viento de esperanza}

En la ruta para preservar la memoria es necesario reconocer los hechos relatados para iniciar un proceso de reparación. El reconocimiento de los hechos es el primer paso para reparar a las víctimas del conflicto emocionalmente y, luego de esto, se construyen garantías para que la víctima se sienta parte de la sociedad civil y se le reconozcan los derechos que le han sido vulnerados. Sin memoria no existe la reparación simbólica, puesto que no existiría la posibilidad de reconocer a la víctima como tal; en otras palabras, como reconocer algo que no se ha visibilizado.

La reparación simbólica es una medida de satisfacción no remunerada que busca la reparación de las víctimas a las que les fueron violentados sus derechos humanos. Este tipo de reparación va más allá de lo monetario, puesto que espera garantizar el derecho a la justicia, la verdad y la no repetición de los hechos, creando un grado de satisfacción mayor al hacer uso de acciones humanas que esperan otorgarles garantías (Maldonado, s.f.). Se debe agregar que la reparación simbólica va de la mano con los procesos de justicia transicional. En Latinoamérica se han estructurado diversos procesos de este tipo, que sirven de ejemplo para el proceso de transición colombiano, tal y como los escenarios de perdón, verdad, sanciones, procedimientos de reconciliación, proporcionalidad e igualdad (Maldonado, s.f.).

La relación entre conflicto y reparación simbólica se puede ver con la correlación que hace Botero (2016) sobre la reestructuración de los derechos de las víctimas con el reconocimiento de la verdad, la memoria, la reunificación familiar, entre otros, en la cual expresa que esta reestructuración no puede darse sin estos factores, los cuales son los que la dotan de sentido, criterio, aproximación a los hechos reales, objetividad y verdad (Rodriguez, 2019). De acuerdo con Rodríguez (2019), los componentes que construyen este tipo de reparación establecen acciones y procesos (como los que se presentan en la tabla 1), en pro de la participación del Estado como garante del proceso de preservación, la construcción de espacios para la preservación de la memoria y la participación activa con cada uno de los actores inmersos en los hechos que se estudien, sean de carácter bélico o pacífico. 
-TABLA 1・Acciones y procesos de reparación

\begin{tabular}{|c|l|}
\hline \multicolumn{2}{|c|}{ Acciones y procesos de reparación } \\
\hline I. & $\begin{array}{l}\text { El Estado como garante de las condiciones para reconstruir la } \\
\text { memoria, la creación del CNMH para recoger, preservar y salvaguardar } \\
\text { materiales pertinentes y relevantes para las víctimas. }\end{array}$ \\
\hline II. & $\begin{array}{l}\text { La construcción del Museo de Memoria para mantener y presentar las } \\
\text { historias de las víctimas del conflicto. }\end{array}$ \\
\hline III. & Realización de investigaciones para construir memoria colectiva. \\
\hline IV. & Recolección de testimonios orales de las experiencias de las víctimas. \\
\hline
\end{tabular}

Fuente: (Rodriguez, Análisis Reparación Simbólica, Una Forma de Revictimización en la Justicia Transicional en Colombia, 2019).

Estas acciones de reparación se han convertido en escenarios para preservar la memoria, al mismo tiempo que se han apoyado en marcos legales. Para el caso colombiano, la Ley de Víctimas (1448 de 2011) para iniciar los procesos de reparación acorde con una hoja de ruta establecida tras la firma del Acuerdo de Paz. A fin de inspeccionar cómo iniciar la reparación simbólica tras los procesos de preservación de memoria, se expondrán algunas leyes a favor de reparar, principalmente en un aspecto simbólico - emocional, a las víctimas del conflicto armado.

En 2011 se constituye la Ley 1448 o Ley de Víctimas, la cual se toma como un marco para consolidar la democracia social a través de una política pública de atención y reparación integral, basada en principios de: progresividad, gradualidad y sostenibilidad. El principio de progresividad, (Artículo 17), se refiere al compromiso de iniciar procesos que conlleven el goce efectivo de los Derechos Humamos, los cuales deben ser garantizados por el Estado e ir acrecentándolos paulatinamente. En cuanto a la gradualidad (Artículo 18), la Ley la define como la responsabilidad estatal de diseñar herramientas operativas de alcance definido en tiempo, espacio y recursos, para implementar programas, planes y proyectos de asistencia y reparación. Finalmente, el principio de sostenibilidad (Artículo 19), es la acción del Gobierno Nacional de crear un Plan Nacional de Financiación, mediante un documento del Consejo Nacional de Política Económica y Social (CONPES) que propenda por la ley de sostenibilidad y fortalezca el Fondo de Reparaciones, establecido en la Ley 975 de 2005 (Centro de Memoria Histórica, s.f.).

La aplicación de la Ley de Víctimas (1448 de 2011) y el proyecto de la Ley de Tierras (reforma a la Ley 160 de 1994) ${ }^{38}$, fortalecen la importancia de la reparación simbólica en las víctimas (Motta \& Trujillo, 2013). A pesar de que la Ley de Tierras se centra en un aspecto de reparación material, al ofrecer un recurso físico a cambio de la declaración de las víctimas, estos factores aportan a que la sociedad sienta el dolor que dejaron los hechos victimizantes, evitando la repetición de la historia (Yepes, 2010).

38 Por la cual se crea el Sistema Nacional de Reforma Agraria y Desarrollo Rural Campesino, se establece un subsidio para la adquisición de tierras, se reforma el Instituto Colombiano de la Reforma Agraria y se dictan otras disposiciones (Ministerio de Agricultura, 1994). 
Los procesos de reparación simbólica tratan de establecer un vínculo entre la víctima y la comunidad, lo que llevaría a la edificación de una sociedad, partiendo de la historia (Rodriguez, 2019). Es decir, aportaría a la construcción y dignificación de la sociedad civil, e incluso serviría como elemento de concienciación para la sociedad, el hecho de reconocer lo sucedido, los daños generados y su evolución, como un cambio drástico para la construcción de memoria y tejido social.

Dentro de las medidas de satisfacción, expresadas en el Artículo 139, la Ley 1448 resalta la difusión pública y completa del relato de las víctimas respecto al hecho victimizante. El relato hace parte de la reconstrucción de los hechos que aportan a la investigación y conducen a la preservación de la memoria (Subcomité Técnico de Medidas de Satisfacción, s.f.). La reparación simbólica derivada de los relatos se presenta como un acto dirigido a la construcción, preservación y recuperación de la memoria histórica, reconocimiento de la dignificación de las víctimas y la reconstrucción del tejido social, además de la asistencia técnica a entidades territoriales en cuanto a medidas de satisfacción y reconocimiento judicial (Alcaldía de Bogotá, 2011).

Desde la escena internacional, se parte del Conjunto de principios para la protección $y$ promoción de los Derechos Humanos para la lucha contra la impunidad (ONU, 2005), estructurado por las Naciones Unidas para la protección de los derechos de las víctimas y a favor del fortalecimiento de sus derechos, la verdad, la justicia, la reparación y las garantías de no repetición (Yepes, 2010). De los principios para la protección y la promoción de los Derechos Humanos, para la lucha contra la impunidad, expuestos por la Organización de las Naciones Unidas (ONU) y el Consejo Económico y Social (ECOSOC), el Principio 33, expresa:

Toda violación de los derechos humanos hace nacer un derecho a la reparación en favor de la víctima, de sus parientes o compañeros que implica, por parte del Estado, el deber de reparar y la facultad de dirigirse contra el autor (ONU; ECOSOC, 1997).

La aplicación de cada uno de estos principios normativos se adhiere a la generación de una reparación efectiva en cada una de las víctimas, la cual promueve la justicia y aporta a la construcción de memoria colectiva, a través de la verdad. La reparación simbólica debe buscar la dignificación y reconocimiento de las víctimas, recordar la verdad de los hechos victimizantes y solicitar perdón por parte de los victimarios, que deberán asumir las responsabilidades (Yepes, 2010).

Establecer un único concepto de reparación simbólica no ha sido tarea fácil, por lo que se analiza un panorama general a través de la visión de distintos autores. Ramírez y Sora (2013) establecen la importancia de realizar un "Tribunal Simbólico", como estrategia para darle a la violencia un tratamiento público proporcional con la gravedad y complejidad que ha tenido este delito en Colombia (Rodriguez, 2019).

A nivel nacional, la reparación simbólica se ha tomado como un compromiso que va más allá de los monumentos, esto quiere decir que este tipo de reparación se asocia a modelos de justicia restaurativa, con el fin de reconciliar a las víctimas del conflicto y sus responsables a través del resarcimiento de los daños ocasionados (Hacemos 
Memoria, 2017). En este punto, es importante reconocer que son las víctimas quienes dan sentido a la reparación simbólica y esta ofrece a cambio la reconstrucción de los lazos sociales; como menciona Helka Quevedo (2014), "Los huesos hablan, las marcas están tatuadas en los restos" (Duque, 2018).

Cada uno de estos relatos aporta a la construcción consecutiva de la reparación simbólica, apegada en Colombia a la Ley 1448 de 2011 o Ley de Víctimas, la cual posibilitó la creación de las siguientes instituciones: 1) la Unidad de Víctimas para la reparación material y atención psicosocial; 2) la Unidad de Restitución para devolver las tierras de las cuales fueron despojados; y, 3) el Centro Nacional de Memoria Histórica (CNMH), el cual tiene como objetivo dar validez al derecho a la verdad y la reparación simbólica de las víctimas (Duque, 2018). Estas instituciones se han convertido en canales de preservación de la memoria y, a su vez, este tipo de reparación se involucra en la sociedad civil y genera preguntas entre las personas, tales como ¿dónde estábamos mientras todo eso estaba pasando?, ¿por qué ocurrió?, ¿qué debemos hacer para borrar las causas que generaron este conflicto y permitieron que se degradara? (Duque, 2018), entre otros interrogantes que aportan al derecho de la reparación y la deconstrucción de lo sucedido en el país.

Un elemento que no puede pasar desapercibido es que el derecho a la reparación parte de una ficción jurídica, la cual trata de pensar el alcance de la compensación que le es debida a la persona por los daños que ha sufrido. La naturaleza del daño puede ser entendida desde lo material y lo simbólico. Historiadores y juristas han afirmado que la reparación simbólica es imposible, porque el conflicto armado ha quebrado vínculos y no admite formas de volver al momento de la fractura (Duque, 2018). Es devolverle el valor a un intangible que se ha fragmentado, la vida, la paz, la tranquilidad, etc. Sin embargo, Colombia se apoya en la Ley de Víctimas (1448 de 2011), que establece medidas de satisfacción y rehabilitación para desarrollar la reparación simbólica. Las acciones de memoria están enfocadas en dichas medidas de satisfacción, es decir, aquellas que están orientadas a dignificar a las víctimas y restablecer su buen nombre; un ejemplo es el texto de la antropóloga de la Comisión Judicial, Helka Quevedo, Textos corporales de la crueldad (2014), en donde se hace memoria a personas sometidas a todo tipo de torturas por parte de grupos paramilitares y busca restablecer su buen nombre y el de sus familias (Duque, 2018).

Halbwachs menciona que la historia comienza donde termina la memoria colectiva (Brito \& Martínez, 2005); su estructuración inicia cuando los grupos portadores de memoria cierran un ciclo en un escenario histórico e inician otro. Sobre esto, las víctimas se han restablecido en espacios de reparación simbólica a través de acciones como Raíces, una iniciativa de siembra en la reserva forestal Thomas Van Der Hammen, de Bogotá, las siembras de las víctimas en este lugar han construido espacios de memoria y paz (Duque, 2018); cada uno de las cultivos representaba hechos de violencia como secuestros, extorsiones, abusos físicos, entre otros, por lo cual este proyecto hace parte de fortalecer la memoria colectiva desde un enfoque divergente que sea capaz de llegarle a la sociedad civil con un mensaje sobre los escenarios de reparación simbólica, la preservación de la memoria y su historia y el papel de los actores víctimas/victimarios en el marco del conflicto. 
Es importante tener en cuenta el dolor que conlleva recordar los sucesos del conflicto, a favor de la preservación de la memoria. Por tal razón, se hace referencia a Paul Ricoeur, filósofo contemporáneo de la historia y la memoria, quien habla del recuerdo como una obligación moral, puesto que va ligado al proceso de justicia que busca responder el qué, cómo y para qué. Dado esto, el autor expone que la condición política de la memoria se condensa en frases como "tú te acordarás" y "no te olvidarás", generando un aspecto traumatizante al momento de preservar la memoria (Jaramillo, 2012).

Este filósofo contemporáneo propone que para la preservación de la memoria se establezca un trabajo de duelo y un trabajo de memoria, siendo estos la expresión de un "olvido emocional del rencor", lo cual conlleva a la reconciliación (Riceur, 2000). Según Ricoeur, es la justicia la que se dirige hacia el otro y constituye el componente de alteridad de todas las virtudes que se extraen de los relatos, para que luego la justicia se conecte con el deber de memoria, el mismo deber de hacer justicia mediante el recuerdo, el cual está ligado con el olvido, considerando que la memoria se encarga de reconstruir el pasado y olvidar de forma restaurativa (Nieto, 2006).

Así la memoria en Colombia se entiende como una forma de resistencia al olvido (Revelo, 2019); las víctimas envueltas en el conflicto armado no tuvieron tiempo para la tristeza, por lo que hasta ahora están buscando la forma de reclamar sus derechos y, al mismo tiempo, de crear espacios de reparación simbólica colectiva. Dentro de las cuales se represente una versión real de lo vivido, la preservación de la historia para posteridad, y de una forma u otra, reclamar los derechos que se les fueron violentados por grupos armados ilegales. Se deben aplicar en su totalidad dichos procesos de Justicia y Paz propuestos por el Gobierno Nacional, ya que estipulan pautas de reparación claras y de preservación de memoria, con el fin de no repetir los hechos devastadores que dejó la violencia.

\section{Conclusiones}

Preservar la memoria es un hecho importante para no dejar en el olvido aquellos elementos que han forjado una identidad, historia, unidad patriótica o país, teniendo en cuenta que la preservación es un hecho tanto nacional como global e implica reconocer y tomar como base momentos de perturbación o guerras pasadas. Es la herramienta capaz de ayudar a reconstruir o deconstruir los acontecimientos producto de episodios de violencia, como es el caso de Colombia. El hecho de reconocer el trasfondo del conflicto interno, sus actores participantes y la reconstrucción de momentos, va encaminada al establecimiento de una versión lo más ajustada posible de la realidad pasada, que influencia en el presente y será vital en el futuro.

Para esto se reconocen dinámicas elaboradas por medio de la reparación simbólica, las cuales permiten un diálogo ameno en el que se reconozca a la víctima y su relato, y en donde inicie el ciclo de preservación de la memoria (individual, colectiva e histórica). La memoria en Colombia se presenta como una forma de reparación simbólica ante la sociedad colombiana, puesto que reconoce la violación de los derechos de las víctimas, ofrece espacios de diálogo que permiten reparar, principalmente, a nivel psicológico a cada uno de los grupos afectados, y expone los hechos ante la sociedad civil para evitar la repetición de estos. Además, la memoria influye en los procesos de 
reparación individual y colectiva, ya que si no se reconocen los hechos no se podría iniciar un proceso para repararlos. Esto es fundamental para expandir las perspectivas internacionales de reparación desde el análisis del conflicto interno colombiano.

Para iniciar un proceso de reparación simbólica es necesario reconocer lo sucedido y el hecho a reparar, por lo que este proceso debe ir de la mano con la preservación de la memoria en escenarios de diálogo, en los cuales se fortalezca emocionalmente a la víctima que narran el relato con incentivos de reparación psicológica y apoyo por parte de la sociedad civil. Se reconoce que el escenario de guerra que ha vivido Colombia por más de cincuenta años, así como otros conflictos internacionales que han sido marcados por periodos bélicos, trae consigo una gran cantidad de víctimas, las cuales se pueden dividir en campesinos, indígenas, Fuerzas Militares, civiles, afros, entre otros, con el fin de establecer la memoria individual. Luego sus relatos se agrupan, puesto que todos fueron víctimas de un mismo conflicto; esto deriva en la construcción de la memoria colectiva, un espacio de edificación más amplio.

Por consiguiente, cada uno de los relatos individuales y en conjunto aportan al reconocimiento de una historia no contada antes. Con la memoria histórica se crea la posibilidad de establecer espacios que involucren a la sociedad civil, la cual reconoce el papel en que se encuentra cada uno de los actores participantes del conflicto. Es decir, que la memoria influye directamente en los espacios de reparación simbólica que aportan a la sociedad civil, puesto que su preservación permite que se conozcan las afectaciones principales a las víctimas. No obstante, no es un camino fácil, aún queda mucho por recorrer y las víctimas tendrán que hacer un recorrido constante en la preservación de memoria para evitar dos elementos: uno, la repetición de los hechos que las colocaron justamente en ese papel, el de víctimas, y, dos, evitar la negación de la memoria, la cual trae a su vez la imposición progresiva de la construcción de nuevas memorias que buscan tergiversar los relatos presentados de lo vivido en el marco del conflicto.

La reincorporación a la vida civil no significa solo una reparación material plasmada en un lugar para vivir; esta va acompañada de una reparación simbólica ante la oportunidad que los actores vulnerados puedan volver a rehacer sus vidas y su historia demarque un antes y un después en la preservación de unos hechos que deben conocerse, pero no repetirse. En el marco del conflicto colombiano (y la firma de un Acuerdo de Paz) la memoria y sus tipos, la reparación simbólica y la sociedad colombiana, representan una ventana de oportunidad para preservar lo vivido, y desde allí ir forjando un presente con mejores condiciones para el futuro, un camino a una paz estable y duradera.

\section{Referencias}

Alcaldía de Bogotá. (2011). Documentos para Ley de Víctimas: medidas de satisfacción y reparación simbólica. Obtenido de SISJUR: https://www.alcaldiabogota.gov.co/ sisjur/listados/tematica2.jsp?subtema=25744\&cadena $=$

Antón, E. G. (Enero de 2017). Ríos, Jerónimo: Breve historia del conflicto armado en Colombia. Obtenido de Universidad Jorge Tadeo Lozano: https://www. researchgate.net/publication/320424697_Rios_Sierra_J_Breve_historia_del_ conflicto_armado_en_Colombia_Madrid_La_Catarata_2016_200_pp 
Aránguiz, T. V. (11 de diciembre de 2014). Victimización y heroísmo. Disputas de las memorias emblemáticas en dos fechas conmemorativas: aniversario del Golpe de Estado y Día del Joven Combatiente. Obtenido de Universidad de Chile: https:// dialnet.unirioja.es/descarga/articulo/5256785.pdf

Ávila, J. T. (8 de julio de 2013). La memoria histórica y las víctimas. Obtenido de Universidad Militar Nueva Granada: http://vip.ucaldas.edu.co/juridicas/ downloads/Juridicas10(2)_9.pdf

Barcelona Centre For International Affairs. (s.f.). Conflicto en Colombia: antecedentes históricos y actores. Obtenido de Dossier proceso de paz en Colombia: https:// www.cidob.org/publicaciones/documentacion/dossiers/dossier_proceso_ de_paz_en_colombia/dossier_proceso_de_paz_en_colombia/conflicto_en_ colombia_antecedentes_historicos_y_actores

BOE Legislación Consolidada. (27 de diciembre de 2007). Ley 52/2007. Obtenido de Jefatura de Estado: https://www.boe.es/buscar/pdf/2007/BOE-A-2007-22296consolidado.pdf

Brito, R. M., \& Martínez, M. A. (Enero - Junio de 2005). Memoria colectiva y procesos sociales . Obtenido de Consejo Nacional para la Enseñanza en Investigación en Psicología: https://www.redalyc.org/pdf/292/29210112.pdf

Camacho, J. F. (2018). La construcción de la memoria histórica como derecho fundamental. Obtenido de Universidad Católica: https://repository.ucatolica. edu.co/bitstream/10983/15809/1/La\%20memoria\%20historica\%20como\%20 derecho\%20fundamental.pdf

Caraballo, L. A., \& Anaya, N. M. (2 de abril de 2016). El conflicto armado interno colombiano: una mirada socio-jurídica desde la jurisprudencia de la Corte Penal Internacional. Obtenido de Justicia Juris. 12 (1), 107-117: http://www.scielo.org. co/pdf/jusju/v12n1/v12n1a10.pdf https://doi.org/10.15665/rj.v12i1.892

Centro de Escritura Javeriano. (Agosto de 2018). Artículo de Reflexión. Obtenido de Pontificia Universidad Javeriana: https://www2.javerianacali.edu.co/sites/ujc/ files/articulo_de_reflexion.pdf

Centro de Memoria Histórica. (s.f.). Ley de Víctimas y Restitución de Tierras. Obtenido de Agencia Presidencial para la Acción Social y la Cooperación Internacional: http://www.centrodememoriahistorica.gov.co/descargas/ley_victimas/ley_ victimas_completa_web.pdf

Centro Nacional de Memoria Histórica. (2014). jBasta Ya! Colombia: Memorias de Guerra y Dignidad. Obtenido de Informe general Grupo de Memoria Histórica: https:// www.centrodememoriahistorica.gov.co/descargas/informes2013/bastaYa/ basta-ya-colombia-memorias-de-guerra-y-dignidad-2016.pdf 
Centro Nacional de Memoria Histórica. (2018). Los caminos de la memoria histórica. Obtenido de Bogotá, CNMH.: http://www.centrodememoriahistorica.gov. co/micrositios/un-viaje-por-la-memoria-historica/pdf/los-caminos-de-lamemoria-historica.pdf

Consejería Presidencial para las Comunidades. (s.f.). Zonas Estratégicas de Intervención Integral. Obtenido de Presidencia: https://id.presidencia.gov.co/ Documents/190808-Infografia-Zonas-Futuro.pdf

Duque, J. I. (2018). Voces que resuenan, un ejercicio de reparación simbólica en el museo de memoria histórica de Colombia. Obtenido de Banco de la República, Boletín Museo del Oro: https://publicaciones.banrepcultural.org/index.php/bmo/article/ view/20786/21211

Durán, C. A., Ángel, M. E., Monsalve, D. Y., \& Sánchez, C. M. (2017). Protegiendo el azul, comprendí el rojo de la bandera: Narrativas desde la Armada. Bogotá, D. C.: Universidad Santo Tomás. https://doi.org/10.15332/li.lib.2017.00081

Echeverry, D. B. (2004). Memoria individual, memoria colectiva y memoria histórica: lo secreto y lo escondido en la narración y el recuerdo. Obtenido de Universidad Pedagógica Nacional (UPN): http://biblioteca.clacso.edu.ar/Colombia/dcsupn/20121130052459/memoria.pdf

ElCorreoGallego. (19 de enero de 2019). La culpa y el pasado. Obtenido de Catedrático de Historia Antigua de la Universidad de Santiago: https://www.elcorreogallego. es/hemeroteca/culpa-pasado-ANCG1160132

Giraldo, M. L. (Junio de 2012). Registro de la memoria colectiva del conflicto armado en Colombia: un estado de la cuestión. Obtenido de Escuela Interamericana de Bibliotecología, Universidad de Antioquia: https://bid.ub.edu/28/pdf/giraldo2. pdf

Gómez, J. D. (2013). Memoria Histórica desde las Víctimas del Conflicto Armado. Obtenido de Kavilando, Vol. 5, No. 1: https://dialnet.unirioja.es/servlet/ articulo?codigo $=5632067$

Gutiérrez, J. M., Andrade, L. M., Huérfano, C. A., \& Cañón, I. A. (Agosto de 2017). Recuperación de la Memoria Histórica y Sistematización de Experiencias en el Costurero de la Memoria: Kilómetros de Vida y de Memoria. Obtenido de Universidad Católica de Colombia, Facultad de Pscología: https://repository.ucatolica.edu. co/bitstream/10983/15150/1/RECUPERACI\%C3\%93N\%20DE\%20LA\%20 MEMORIA\%20HIST\%C3\%93RICA\%20Y\%20SISTEMATIZACI\%C3\%93N\%20 DE\%20EXPERIENCIAS.\%20COSTURERO\%20DE\%20LA\%20MEMORIA.pdf

Hacemos Memoria. (9 de mayo de 2017). Reparación Simbólica: un compromiso que va más allá de los monumentos. Obtenido de http://hacemosmemoria.org/2017/05/09/ reparacion-simbolica-un-compromiso-que-va-mas-alla-de-los-monumentos/ 
Halbwachs, M. (1991). Fragmentos de La Memoria Colectiva. Obtenido de Revista de Cultura Psicológica, Año 1, Número 1, México, UNAM. Facultad de Psicología: https://ddd.uab.cat/pub/athdig/15788946n2/15788946n2a5.pdf https://doi. org $/ 10.5565 / \mathrm{rev} /$ athenead/v1n2.52

Hurtado, M. (23 de abril de 2006). Proceso de reforma constitucional y resolución de conflictos en Colombia: El Frente Nacional de 1957 y la Constituyente de 1991. Obtenido de Revista de Estudios Sociales: https://journals.openedition.org/ revestudsoc/22356 https://doi.org/10.7440/res23.2006.08

Huyssen, A. (2002). En busca del futuro perdido. Cultura y memoria en tiempo de globalización, México, FCE. Obtenido de Instituto de Investigaciones "Gino Germani”, Universidad de Buenos Aires: http://sedici.unlp.edu.ar/bitstream/ handle/10915/13716/Documento_completo.pdf?sequence=1\&isAllowed=y

Iglesias, L. E. (Enero-Junio de 2010). Memoria y Resiliencia. Obtenido de Universidad Militar Nueva Granada: https://www.redalyc.org/pdf/876/87617271006.pdf

Jaramillo, J. (30 de abril de 2012). Los fundamentos de una política de la justa memoria. Obtenido de Pontificia Universidad Javeriana: http://www.scielo.org.co/pdf/ef/ n46/n46a04.pdf

Loaiza, A. G. (Mayo de 2012). Negociaciones de paz en Colombia, 1982-2009. Un estado del arte. Obtenido de Corte Interamericana de Derechos Humanos: https:// corteidh.or.cr/tablas/r30706.pdf

Maldonado, S. Y. (s.f.). Reparación simbólica como mecanismo de acceso a la justicia de las víctimas del conflicto armado en Colombia. Obtenido de Universidad Santiago de Cali, Facultad de Derecho: https://repository.usc.edu.co/bitstream/ handle/20.500.12421/3525/REPARACI\%C3\%93N\%20SIMB\%C3\%93LICA. pdf? sequence $=1 \&$ isAllowed $=y$

Marín, J. J. (28 de abril de 2011). El giro hacia el pasado. Reflexiones sobre su naturaleza e impactos. Obtenido de Universidad del Valle: https://revistas.pedagogica.edu.co/ index.php/RF/article/view/731

Ministerio de Agricultura. (5 de agosto de 1994). Ley 160 de 1994. Obtenido de Congreso de Colombia: https://www.minagricultura.gov.co/Normatividad/ Leyes/Ley\%20160\%20de\%201994.pdf

Montoya, P. P. (s.f.). ¿Por qué se dio el Estatuto de Seguridad? La Comisión busca respuestas. Obtenido de Hacemos Memoria: http://hacemosmemoria.org/2020/08/21/porque-se-dio-el-estatuto-de-seguridad-la-comision-busca-respuestas/

Motta, A. R., \& Trujillo, F. A. (2013). Ensayo sobre la reparación a las víctimas del conflicto armado en Colombia. Obtenido de Universidad Militar Nueva Granada: https://repository.unimilitar.edu.co/bitstream/handle/10654/10656/ RamirezMottaAlexander2013.pdf?sequence $=2$ 
Nieto, J. (Junio de 2006). El deber de la memoria, la imposibilidad del olvido. Obtenido de Universidad Autónoma de Bucaramanga: https://www.redalyc.org/ pdf/110/11001507.pdf

ONU. (8 de febrero de 2005). Conjunto de principios para la protección y promoción de los Derechos Humanos para la lucha contra la impunidad. Obtenido de http://www. derechos.org/nizkor/impu/impuppos.html

ONU; ECOSOC. (2 de octubre de 1997). La cuestión de la impunidad de los autores de violaciones de los derechos humanos (civiles y políticos). Obtenido de Informe final elaborado y revisado por M. Joinet: http://www.derechos.org/nizkor/doc/ joinete.html

Policía Nacional de Colombia. (2020). Memoria Histórica Institucional. Obtenido de Área de Historia, Memoria Histórica y Víctimas: https://policia.edu.co/memoria/wpcontent/uploads/2020/04/cartilla-memoria-historica.pdf

Revelo, L. R. (19 de agosto de 2019). Memoria, reparación simbólica y arte: la memoria como parte de la verdad. Obtenido de Foro: revista de derecho: https://1library. co/document/zxv862vy-memoria-reparacion-simbolica-arte-memoria-parteverdad.html

Riceur, P. (2000). La memoria, la historia, el olvido. Obtenido de Fondo de Cultura Económica: http://mastor.cl/blog/wp-content/uploads/2015/08/RICOEUR-P.La-memoria-la-historia-el-olvido-LAV.pdf

Rodriguez, C. E. (22 de mayo de 2019). Análisis Reparación Simbólica, una forma de revictimizaciónenlajusticiatransicionalen Colombia.ObtenidodeUniversidadLibrede Colombia: https://repository.unilibre.edu.co/bitstream/handle/10901/17809/ AN\%C3\%81LISIS\%20REPARACI\%C3\%93N\%20SIMB\%C3\%93LICA, \% 20 UNA\%20FORMA\%20DE\%20REVICTIMIZACI\%C3\%93N\%20EN\%20LA\%20 JUSTICIA\%20TRANSICIONAL\%20EN\%20COLOMB.pdf?sequence=1

Rodriguez, C. E. (22 de mayo de 2019). Análisis Reparación Simbólica, Una Forma de Revictimización en la Justicia Transicional en Colombia. Obtenido de Universidad Libre de Colombia: https://repository. unilibre.edu.co/bitstream/handle/10901/17809/AN\%C3\%81LISIS\%20 REPARACI\%C3\%93N\%20SIMB\%C3\%93LICA\%2C\%20UNA\%20FORMA\%20 DE\% 20REVICTIMIZACI\% C3\% 93N\% 20EN\% 20 LA\% 20JUSTICIA\% 20 TRANSICIONAL\%20EN\%20COLOMB.pdf? sequence=1\&isAllowed=y

Sánchez, C. A. (2016). Análisis de Prácticas y Experiencias Comunicativas de las Memorias del Conflicto Armado Colombiano. Obtenido de Universidad Distrital Francisco José de Caldas: https://repository.udistrital.edu.co/ bitstream/handle/11349/2723/AcostaS\%E1nchezCeciliaAndrea2016. pdf;jsessionid $=5$ C95849B48D6A85714A9F8966D1982A0? sequence $=1$ 
Serrano, J. A. (18 de octubre de 2018). La desigualdad en el reparto de la tierra en Colombia: Obstáculo principal para una paz duradera y democrática. Obtenido de Anales de Geografía de la Universidad Complutense: https://revistas.ucm.es/ index.php/AGUC/article/download/62486/4564456548708/

Siedl, A. (s.f.). Memoria Individual, Memoria Colectiva y Memoria Nacional. Obtenido de https://www.bibliopsi.org/docs/carreras/obligatorias/CFG/03social/zubieta/ primer\%20cuatrimestre\%202020/Practicos/Memoria\%20individual,\%20 memoria\%20colectiva,\%20memoria\%20nacional\%20-\%20L.\%20Siedl.pdf

Subcomité Técnico de Medidas de Satisfacción. (2011). Guía de medidas de satisfacción. Obtenido de Gobierno de Colombia: https://gapv.mininterior.gov.co/sites/ default/files/guia_de_medidas_de_satisfaccion.pdf

Subcomité Técnico de Medidas de Satisfacción. (s.f.). Guía de medidas de satisfacción. Obtenido de Gobierno de Colombia: https://gapv.mininterior.gov.co/sites/ default/files/guia_de_medidas_de_satisfaccion.pdf

Vásquez, H. T. (Julio - Diciembre de 2010). El concepto de terrorismo de Estado: una propuesta de Lege Ferenda. Obtenido de Universidad Libre: https://dialnet. unirioja.es/descarga/articulo/3618445.pdf

Vásquez, H. T. (26 de febrero de 2015). Posconflicto colombiano, el dilema de la nueva lucha contra el terrorismo. Obtenido de Universidad La Gran Colombia: http:// www.scielo.org.co/pdf/jusju/v11n1/v11n1a10.pdf https://doi.org/10.15665/ rj.v11i1.622

Yepes, Á. A. (Julio - Diciembre de 2010). Las Reparaciones Simbólicas en Escenarios de Justicia Transicional. Obtenido de Corte Interamericana de Derechos Humanos: https://www.corteidh.or.cr/tablas/r27292.pdf 